\title{
An anaerobic side-stream reactor in wastewater treatment: a review
}

\author{
R. Ferrentino, M. Langone, G. Andreottola \& E. C. Rada \\ Department of Civil, Environmental and Mechanical Engineering, \\ Trento University, Italy
}

\begin{abstract}
In the frame of a modern waste management, an important sector concerns the sewage sludge minimisation. In recent years a lot of techniques have been developed to reduce the sludge production such as biological, thermal, thermochemical, high temperature oxidation and mechanical treatments, ultrasonication and ozonation or by using chemical compounds. Some of these have been proven to be not energy saving technologies, while others could negatively affect the effluent quality of the process due to the formation of byproducts. Among those, the use of an anaerobic side-stream reactor (ASSR) in the conventional activated sludge line is considered a challenging biological technology to minimize the sludge production in wastewater treatment plants.

The whole process is mainly based on the waste activated sludge recirculation between aerobic, anoxic and anaerobic conditions. The ASSR can be easily realized in both new and existing plants as it consists of an anaerobic side-stream reactor for sludge treatment and reduction where a portion or, in some cases, all the excess sludge of the activated sludge process is recycled. Studies show that combining a conventional activated process with an ASSR could reduce the sludge yield by up to $40-60 \%$ without any negative effects, neither on the effluent quality nor on the settling characteristics of the activated sludge. The process has been applied by using various configurations. Further, different explanations about the reduction mechanism behind the process have been provided. This paper is a review of the existing application of the ASSR, in order to describe the configurations implemented, the mechanisms of sludge reduction observed and the main parameters involved.

Keywords: anaerobic side-stream reactors (ASSR), ASSR configurations, reduction mechanisms, sludge reduction.
\end{abstract}




\section{Introduction}

Nowadays, the most used process for treating civil and industrial wastewaters is the conventional activated sludge process (CAS) that allows to obtain a high organic removal efficiency producing, on the other hand, a large amount of excess sludge to be disposed. The production of excess sludge in municipal wastewater treatment plants (WWTPs) has increased due to more stringent legislation and a growing number of new plants, becoming a critical issue. Processing excess sludge could account for $25-65 \%$ of the total operation costs of a wastewater treatment plant [1-3] and its disposal costs have become more and more expensive due to restriction in reuse and disposal.

A modern waste management is based on the following hierarchy: prevention (viewed as minimization of the generated residues), reuse (involving checking, cleaning, repairing etc.), recycling and recovery. Disposal must be the last viable option. In this frame an important sector concerns sewage sludge minimisation.

In recent years a lot of techniques have been developed to reduce the sludge production in WWTPs such as biological, thermal, thermochemical, high temperature oxidation and mechanical treatments, ultrasonication, ozonation or using chemical compounds [4-10]. To reach a significant sludge reduction some of these has been proven to be not energy saving technologies, while others can negatively affect the effluent quality of the process due to the formation of byproducts. A biological technology based on sludge cycling between aerobic, anoxic and anaerobic conditions has been developed to minimize activated sludge production [11]. This process can be applied by using various configurations. It fundamentally consists of an aeration basin, a settling tank and an anaerobic side-stream reactor (ASSR) for sludge treatment and reduction where a portion or, in some cases, all the excess sludge is recycled. Semblante et al. [12], in a recent review, report that this cycling process was first applied to wastewater treatment by Westgarth et al. [13], inserting an anaerobic tank in the return sludge line and achieving up to $50 \%$ of reduction in sludge production. More recent studies demonstrated that using an ASSR, the sludge yield could be reduced by up to $40 \%[14], 55 \%[2,15]$ and $60 \%$ [16] compared to a conventional biological process. The process showed to be useful in terms of sludge reduction, simple to realize in existing wastewater treatment plants, energy saving and without negative effects for the effluent quality. However, different explanations about the reduction mechanism have been proposed such as enhancing endogenous decay, the metabolic uncoupling, the feasting/fasting mechanism, the destruction of EPS, a domination of slow-growing microorganism and the predation of bacteria. Thus, the aim of the this paper is to present an overview of the existing application of ASSR in order to describe the configurations implemented, the mechanisms of sludge reduction observed and the main parameters involved. 


\section{Anaerobic side-stream configurations}

The ASSR technology has been developed using several configurations. The aim of this paragraph is to explain and describe the main configurations reported in literature and the main parameters involved.

\subsection{The CAS-OSA configuration}

The CAS-OSA (oxic-settling-anaerobic) process is the simplest configuration achieved by the integration of the ASSR within the conventional activated sludge (CAS) line. The return sludge, extracted from the settling reactor, is pumped into an anaerobic reactor and then is cycled in the activated sludge system and subjected to aerobic conditions (fig. 1).

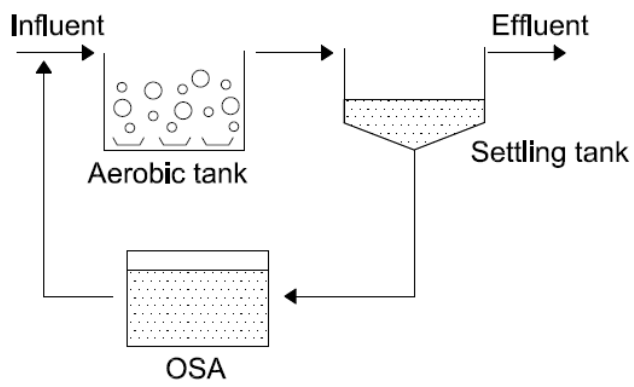

Figure 1: OSA-activated sludge configuration.

The study of Westgarth et al. [13] reports the first application of the OSA process in wastewater treatment plants. Results show that subjecting the activated sludge to a period of anaerobiosis could reduce the production of excess sludge up to $50 \%$ compared to a common activated sludge process. Then the process has been developed and tested by Chudoba et al. [14, 17]. Two continuous activated sludge units were considered: the first one operated with the CAS and OSA system, the second one only with CAS as control unit. Results show an enhancement in phosphate removal, a suppression of activated sludge filamentous bulking, the reduction of the excess sludge production and no negative effects on the effluent quality. The systems were operated at the same HRT, fed with synthetic substrate and considering a sludge retention time (SRT) equal to 3 hours. Based on this assumption, Ye et al. [18] investigate the effect of the SRT on excess sludge producing in the OSA activated sludge process. Three OSA system were studied with SRT equal to $5.5 \mathrm{~h}, 7.6 \mathrm{~h}$ and $11.5 \mathrm{~h}$. Results show a decrease in sludge production for all the system implemented but the best performance was obtained with the OSA system operated with the highest SRT. 


\subsection{The MBR-OSA configuration}

The MBR-OSA configuration can be considered an alternative solution to the process explained above. The main difference is the use of a membrane bioreactor (MBR) instead of the conventional activated sludge (CAS) process (fig. 2).

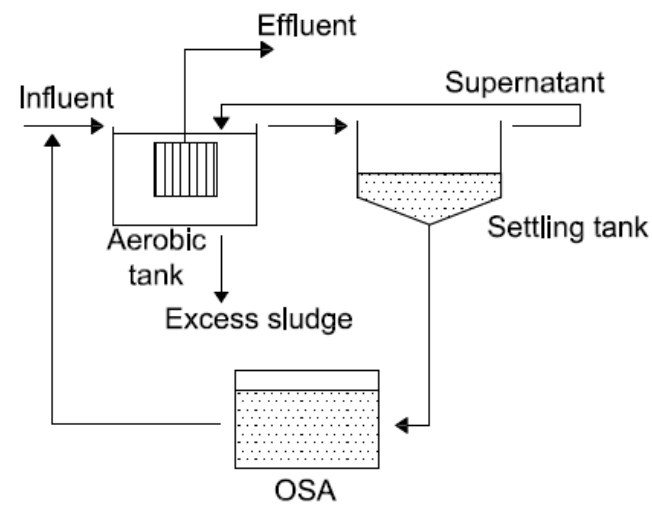

Figure 2: MBR-OSA configuration.

The configuration consists of an aerobic tank where a hollow-fiber membrane module is employed, a settling tank and a sludge holding tank. The settled sludge is pumped to the anaerobic reactor while the supernatant is recirculated to the aeration tank to avoid undesired loss of sludge.

Using the MBR-OSA configuration, Chen et al. [15] observed about 23-51\% of sludge reduction, compared to a conventional MBR system.

This configuration was also used by Saby et al. [2] to investigate the effect of low ORP on the excess sludge production. Different ORP value were investigated. Results show a sludge production equal to $0.17,0.21$ and $0.29 \mathrm{~kg}$ $\mathrm{TSS} / \mathrm{Kg}$ COD corresponding, respectively, to an ORP value of $-250,-100$ and $+100 \mathrm{mV}$. The influence of the ORP value on the sludge production, by using the MBR-OSA configuration, was confirmed also by An and Chen [19].

\subsection{The SBR-OSA configuration}

The SBR (sequencing batch reactor) - OSA configuration is widely used in literature and in lab-scale applications. It consists of a main reactor operated with cycles per day, mainly four, with four phase (fill, react, settle and decant) and an ASSR where about $10 \%$ of the settle sludge is recirculated. An equal volume from the ASSR is returned to the SBR (fig. 3).

The main differences between this configuration and the CAS- OSA and the MBR-OSA configurations are the lower space requirement in the water line due to the absence of the secondary settling and the intermittent sludge cycling to the ASSR which involves long HRT. 


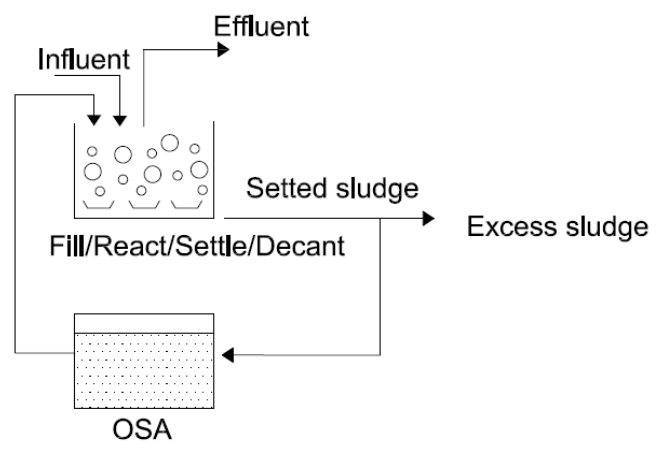

Figure 3: The SBR configuration.

Based on the results obtained by Novak et al. [16] and Goel and Noguera [23], the first who developed the SBR configuration to evaluate the simultaneous nutrient removal and sludge reduction was Datta et al. [25]. The SBR was operated at 4 cycle/day. Two different cycles were tested: the first with a fill and anaerobic, aerobic, anoxic, settling and decant periods while, the second with a fill and anaerobic, aerobic, anoxic, aerobic, settling and decant periods. Results show about $63 \%$ of sludge reduction compared to the control system. Comparing the two different cycles, Datta et al. report that during the first cycle it was possible to achieve a greater sludge reduction than the second one.

Chon et al. [11, 26] applied this configuration by using four laboratory activated sludge systems in order to compare the results: (1) a SBR with an ASSR; (2) a SBR with an aerobic digester; (3) a SBR with an anaerobic digester and (4) a control-SBR. In all the systems, the SBR was operated at 1 day of HRT, while the ASSR and the digester were maintained at 10 day HRT which was equal to SRT. The solid production of the system with a SBR and ASSR was $40-55 \%$ less than the other systems.

\subsection{The Cannibal process}

The Cannibal ${ }^{\circledR}$ reduction process, patented by Siemens Water Technologies, has been developed as a combination of biological and physical treatment. The process is composed of the following parts [20, 21]: (1) a solid separation module; (2) a side-stream interchange bioreactor; and (3) a control system (fig. 4).

Only a portion of the return activated sludge, about $50 \%$, is pumped to the solid separation module which contains a drum screen with hydrocyclones to remove trash, grit, and inert material that accumulates in the mixed liquor due to their small size. The residue produced by the solids separation module can be compressed and disposed of as screenings waste. After the physical treatment, the return sludge flow is directed to the side-stream interchange bioreactor where particular environmental conditions are provided by the automatic control system. A pH and ORP threshold values are ensured to avoid fermentative phenomena with a consequent emission of odours. 


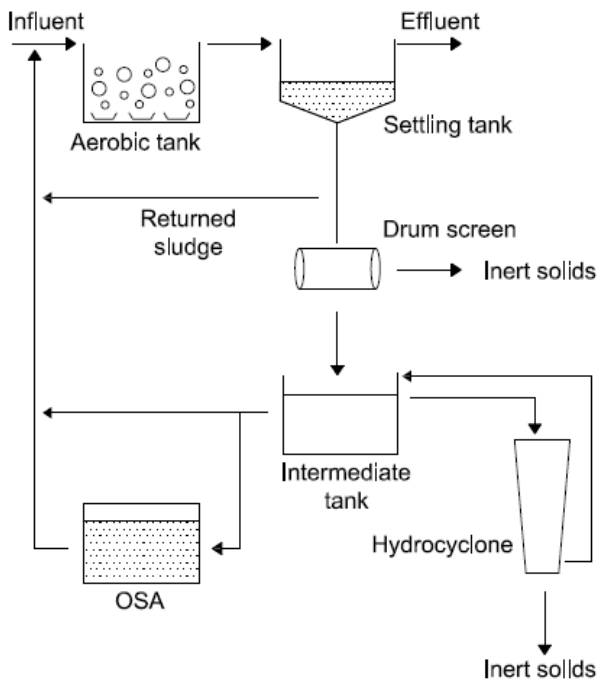

Figure 4: $\quad$ The Cannibal ${ }^{\circledR}$ process configuration.

Novak et al. [16] conducted the first study at laboratory scale, using synthetic feed, in order to evaluate the amount of solid reduced by the Cannibal process, the effect on the effluent quality and on the sludge settling properties. The configuration provided a sequencing batch reactor (SBR) as the main reactor and an ASSR as interchange reactor without a solid separation module. Results show that the Cannibal process generated $60 \%$ less solids than the conventional process without any negative effects neither on the effluent quality nor on the settling characteristics of the activated sludge [16]. The study reports that the main operative parameters of the process are the HRT in the ASSR and the interchange rate (the rate of solids passed through the Cannibal bioreactor, expressed as percentage per day of the biomass in the activated sludge reactor). The HRT depends on the ratio between the volume and the influent sludge flow; values higher than 7 days has to prefer [4]. The interchange rate is an important parameter for the design of the Cannibal process because increasing the interchange rate from 4 to $7 \%$ occurs in a decrease in the solids generation for the Cannibal system. Its optimal value has to be equal to $10 \%$ [4].

The Cannibal process has been investigated also by Goel and Noguera [23] to verify simultaneously the minimization of the sludge production and the improvement in the biological phosphorus removal (EBPR). The Cannibal EBPR system was simulated with an SBR and a chemostatic ASSR. The results were compared with a bench-scale Control-EBPR system. The SBR operates with 4 cycle/day and 3 stages: (1) fill and anaerobic period insured by the injection of nitrogen gas; (2) aerobic react period supplying air; (3) settling and decant phase. At the end of each cycle, $10 \%$ of the settle sludge was transferred from the SBR to the ASSR. The Cannibal- EBPR was operated with a HRT of 10 days. Results show that the Cannibal - EBPR system provides a 16-33\% 
reduction in volatile suspended solids (VSS) and 21-37\% reductions in total suspended solids (TSS) compared to a Control-EBPR system. Regarding the improvement in the phosphorus removal, the study shows a higher removal $(98 \%)$ in the Cannibal-EBPR system than in the Control- EBPR system (84\%).

\subsection{The BIMINEX process}

Biminex $^{\circledR}$ is a new process developed by Coma et al. [24]. The aim is to use a side-stream reactor, to reduce the production of excess sludge, combining with an alternation of anaerobic, anoxic and aerobic condition in water line, to reduce the content of nutrients. The process is a modified configuration of the University of Cape Town (UCT) process that provided only the nutrient removal by an alternation of different ORP environment in the water line. In the BIMINEX $^{\circledR}$ process the returned activated sludge is divided into two lines: the first one allows the recirculation of the sludge into the anoxic tank while the second one leads to the ASSR and then returned to the anaerobic reactor (fig. 5).

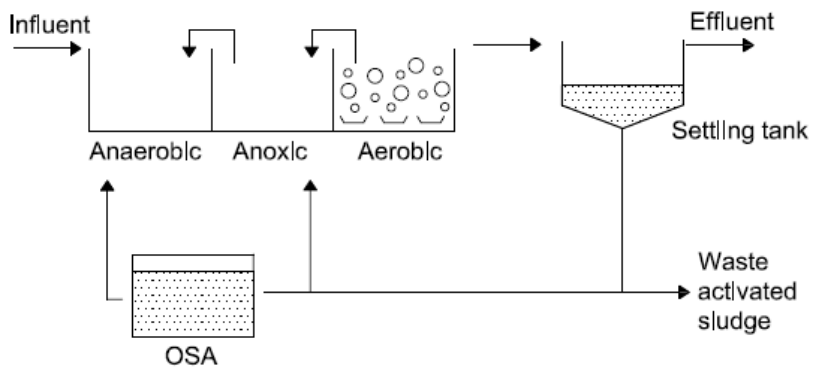

Figure 5: The BIMINEX ${ }^{\circledR}$ process configuration.

This configuration was tested with different percentage of activated returned sludge sent to both the line. The ORP value of the ASSR was fixed at $-150 \mathrm{mV}$. Results show a higher reduction in the sludge production increasing the amount of returned sludge treated in the ASSR. A $18.3 \%$ of sludge reduction, compared to the UTC process, was obtained when $100 \%$ of return sludge was pumped to the ASSR, with HRT values of the water line and the ASSR of $24 \mathrm{~h}$ and $5.9 \mathrm{~h}$, respectively and SRT values of the water line and the ASSR of 17.4 days and 0.2 days, respectively. The reduction obtained is lower compared to the other literature studies. Coma et al. [24] justified this evidence reporting that most of the literature application were carried out in lab-scale reactor using synthetic feed and ideal operating conditions such as long SRT or additional external chemical metabolic uncouples. Thus, the study reports that the main parameter which influenced the process is the sludge loading rate. No explanations were provided about this implication.

\section{Mechanisms}

The aim of this paragraph is to describe the main mechanisms reported in the studies mentioned in this review. Several explanations have been provided about 
the sludge reduction achieved by using the configurations reported above and different mechanisms have been proposed and observed such as endogenous decay, the metabolic uncoupling, the feasting/fasting mechanism, the destruction of EPS, the domination of slow-growing microorganisms and the predation of bacteria

Chudoba et al. [14], applying a CAS-OSA configuration observed a significant sludge reduction. They explain this results noting that the insertion of an anaerobic reactor in the CAS involves a modification on the microbial metabolism of microorganisms, resulting in two phenomena: the metabolic selection of slow growing bacteria and the energetic uncoupling between catabolism and anabolism. The slow growing bacteria present in the CAS-OSA system were the poly-P bacteria. They were $50-60 \%$ of the total bacteria population and the dominant microorganisms of the mixed culture responsible of the enhancement in phosphorus removal. They are able to accumulate polyphosphates under oxic conditions and use them in aerobic conditions as energy source. On the other hand, the cycle passage from an anaerobic to an aerobic environment, also defined "sludge fasting/feasting", submits microorganisms to a stress conditions promoting the uncoupling between catabolism and anabolism. In the anaerobic reactor, where food is insufficient, microorganisms spent their energy to satisfy their maintenance functions but not for the synthesis of new cells while in the aerobic reactor they have enough substrate and rebuilt energy reserves. The cyclic transitions from an anaerobic to an aerobic environment cause a reduction in the sludge production.

The study of Chen et al. [15], using MBR-OSA configuration, investigates four mechanisms which could be possible causes of the excess sludge reduction in the OSA process. The reduction mechanisms investigates were: the energy uncoupling, the domination of slow growing bacteria, the soluble microbial products (SMP) effects and the sludge decay. Comparing the four scenario, Chen et al. defined the sludge decay as the mechanism underlying the sludge reduction in the OSA system. Furthermore the endogenous sludge decay depends on the ORP value: for a lower ORP value applied there is an increase in the endogenous sludge decay coefficient. The same configuration was used also by An and Chen [19]. To understand the excess sludge reduction mechanism they analyzed the balance of the chemical oxygen demand (COD). They assigned the increase of COD concentration into the reactors to the conversion of biomass COD into soluble COD during the sludge decay and then converted mainly to methane gas and carbon dioxide causing a reduction in the sludge production.

Chon et al. [26] studied the ESP destructuration mechanism. They did a quantitative analysis of proteins and polysaccharides extracted from three systems: (1) SBR-ASSR system, (2) SBR with an anaerobic digester and (3) SBR. Results show that protein and polysaccharides were much lower in the first system. Their degradation did not occurs in the activated sludge system even with long SRT but only subjecting the sludge to aerobic and anaerobic conditions. Furthermore, Kim et al. [27] investigated the bacteria community present in the activated sludge with an ASSR system. Microbial analysis show 
similar microorganism in the ASSR and anaerobic digester while some unique cells were present in the ASSR system, including slow growing microorganisms.

To explain the mechanism underlying the Cannibal process, Novak et al. subjected the centrate from the Cannibal process and from the control bioreactor to the oxygen uptake rate test (OUR) and to the analysis of protein concentrations. The test showed that the OUR for the centrate from the Cannibal system was higher than that of the control system due to a higher content of readily biodegradable material that can be easily degraded in the aeration tank. The same result was obtained also by the analysis of proteins. Thus, Novak et al. [16] confirmed the digestion theory underlying the ESP destructuration mechanism, reported in previous studies and based on the release of ironassociated proteins in anaerobic environment that could then easily degraded in an aerobic environment, producing calcium and magnesium associated polysaccharides [22].

\section{Conclusions}

A synthetic summary of the configurations reported in the previous paragraphs, the percentage of sludge reduction, the main operative parameters such as the SRT, HRT and recirculation ratio, and the sludge reduction mechanisms observed are presented in the table below.

Table 1: Overview of the configuration, operational conditions and sludge reduction mechanisms of several pilot and full scale ASSR.

\begin{tabular}{|c|c|c|c|c|c|c|c|}
\hline Ref. & Configuration & $\begin{array}{l}\text { SRT } \\
\text { (d) }\end{array}$ & $\begin{array}{l}\text { HRT } \\
\text { (h) }\end{array}$ & $\begin{array}{l}\text { ORP } \\
(\mathrm{mV})\end{array}$ & $\begin{array}{c}\text { Interchange } \\
\text { rate } \\
(\%)\end{array}$ & $\begin{array}{l}\text { Sludge } \\
\text { reduction } \\
(\%)\end{array}$ & $\begin{array}{c}\text { Reduction } \\
\text { mechanism }\end{array}$ \\
\hline [14] & CAS -OSA & 5 & 3 & -250 & 100 & 40 & $2-3-5$ \\
\hline [17] & CAS -OSA & 12 & 3 & -250 & 100 & 55 & $2-3-5$ \\
\hline [15] & MBR -OSA & 17 & 10.6 & +100 & 100 & 23.4 & 1 \\
\hline [15] & MBR -OSA & 17 & 10.6 & -100 & 100 & 23.4 & 1 \\
\hline [15] & MBR -OSA & 17 & 10.6 & -250 & 100 & 58 & 1 \\
\hline$[2]$ & MBR -OSA & 19.5 & 11 & +100 & 100 & 20 & 1 \\
\hline [2] & MBR -OSA & 25.9 & 15 & -100 & 100 & 45 & 1 \\
\hline [2] & MBR -OSA & 30.4 & 11 & -250 & 100 & 55 & 1 \\
\hline$[16]$ & CANNIBAL & 80 & 10 & - & $4-7$ & 44 & 4 \\
\hline [16] & CANNIBAL & 80 & 1 & - & $4-7$ & 59 & 4 \\
\hline [23] & CANNIBAL & - & - & - & 10 & $16-33$ & 5 \\
\hline [24] & BIMINEX & 23.3 & 34.5 & -150 & 10 & 0.2 & - \\
\hline [24] & BIMINEX & 23.2 & 11.8 & -150 & 50 & 8.9 & - \\
\hline [24] & BIMINEX & 26.2 & 5.9 & -150 & 100 & 18.3 & - \\
\hline [25] & SBR-SSR & 100 & 18 & - & 4.5 & 63 & - \\
\hline $\begin{array}{l}{[11]} \\
{[26]}\end{array}$ & SBR-SSR & 74 & 10 & - & $<10$ & 15 & 4 \\
\hline
\end{tabular}


It has to be taken into account that all of the studies here reported, except the one conducted by Coma et al. [24], have been developed using a synthetic feed. Nevertheless, the table above shows that by varying the configuration it is possible to achieve a different percentage of sludge reduction. Furthermore, until today it has not been possible to define the unique reduction mechanism involved. Nevertheless, the mechanism which has been proposed frequently is related to the sludge endogenous decay and the EPS destructuration mechanism. The role of a slow growing microorganism should be properly verified. Further investigations must be undertaken to completely understand which mechanism could be dominant on the sludge reduction.

\section{References}

[1] Chen, G.-H., Yip, W.-K., Mo, H.-K. \& Liu, Y., Effect of sludge fasting/feasting on growth of activated sludge cultures. Water Research, 35 (4), pp. 1029-1037, 2001.

[2] Saby, S., Djafer, M. \& Chen, G.H., Effect of low ORP in anoxic sludge zone on excess sludge production in oxic-settling-anoxic activated sludge process. Water Research, 37, pp. 11-20, 2003.

[3] Yang, S.-S., Guo, W.-Q., Zhou, X.-J., Meng, Z.-H, Liu, B. \& Ren, N.-Q., Optimization of operating parameters for sludge process reduction under alternating aerobic/oxygen-limited conditions by response surface methodology. Bioresource Technologies, 102 (21), pp. 9843-9851, 2011.

[4] Foladori, P., Andreottola, G. \& Ziglio, G., (eds). Sludge Reduction Technologies in Wastewater Treatment Plants, IWA Publishing London, 2010.

[5] Wei, Y., Van Houten, R.T., Borger, A.R., Eikelboom, D.H. \& Fan, Y., Minimization of excess sludge production for biological wastewater treatment. Water Research, 37, pp. 4453-4467, 2003.

[6] Carrère, H., Dumas, C., Battimelli, A., Batstone, D.J., Delgenès, J.P., Steyer, J.P. \& Ferrer, I., Pretreatment methods to improve sludge anaerobic degradability: a review. Journal of Hazardous Material, 183 (13), pp. 1-15, 2010.

[7] Pilli, S., Bhumia, P., Yan, S., LeBlanc, R.J., Tyagi, R.D. \& Surampalli, R.Y., Ultrasonic pretreatment of sludge: a review. Ultrason. Sonochem., 18, pp. 1-18, 2011.

[8] Chu, L., Yan, S., Xing, X.-H., Sun, X. \& Jurcik, B., Process and perspectives of sludge ozonation as a powerful treatment method for minimization of excess sludge production. Water Research, 43 (7), pp. 1811-1822, 2009.

[9] Hii, K., Baroutian, S., Parthasarathy, R., Gapes, D. J. \& Eshtiaghi N., A review of wet air oxidation and thermal hydrolysis technologies in sludge treatment. Bioresour. Tecnhnol., 155C, pp. 289-299, 2013.

[10] Liu, Y., Chemically reduced excess sludge production in activated sludge process. Chemosphere, 50 (1), pp. 1-7, 2003. 
[11] Chon, D.H., Rome, M., Kim, Y.M., Park, K. Y. \& Park, C, Investigation of the sludge reduction mechanism in the anaerobic side-stream reactor process using several control biological wastewater treatment processes. Water Research, 45 (18), pp. 6021-6029, 2011.

[12] Semblante, G. U., Hai, F. I., Ngo, H. H., Guo, W., Tou, S.-J, Price, W. E. \& Nghiem, L.D., Sludge cycling between aerobic, anoxic and aerobic regimes to reduce sludge production during wastewater treatment: performance, mechanisms and implications. Bioresour. Technol., http://dx.doi.org/10.106/j.biortech.2014.01.029, 2014.

[13] Westgarth, W., Sulzer, F. \& Okun, D., Anaerobiosis in the activated sludge process. Proc. of the $2^{\text {nd }}$ IAWPRC Conference, pp. 43-55, 1964.

[14] Chudoba, P., Morel, A. \& Capdeville, B., The case of both energetic uncoupling and metabolic selection of microorganisms in the OSA activated sludge system. Environ. Technol., 13, pp. 761-770, 1992.

[15] Chen, G.-H., An, K.-J., Saby, S., Brois, E. \& Djafer, M., Possible cause of excess sludge reduction in an oxic-settling-anaerobic activated sludge process (OSA process). Water Research, 37, pp. 3855-3866, 2003.

[16] Novak, J. T., Chon, D.H., Curtis, B.S. \& Doyle, M., Biological solids reduction using the cannibal process. Water Environ. Res., 37, pp. 23802386, 2007.

[17] Chudoba, P., Chudoba, J. \& Capdeville, B., The aspect of energetic uncoupling of microbial growth in the activated sludge process - OSA system. Water Science Technol., 26 (9-11), pp. 2477-2480, 1992.

[18] Ye, F.-X., Zhu, R.-F. \& Li, Y., Effect of sludge retention time in sludge holding tank on excess sludge production in the oxic-settling-anoxic (OSA) activated sludge process. Journal of Chemical Technol. And Biotechnol., 83, pp. 109-114, 2008.

[19] An, K.-J \& Chen, G.-H., Chemical oxygen demand and the mechanism of excess sludge reduction in an oxic-settling-anaerobic activated sludge process. Journal of Environmental Engineering, 134, pp. 469-477, 2008.

[20] Siemens, www.water.sismens.com (accessed January 2013)

[21] Ragazzi, M., Rada, E.C., Ferrentino, R., Analysis of a real scale experiences of novel sewage sludge treatments in an Italian pilot region. Proceeding of the $13^{\text {th }}$ International Conference on Environmental Science \& Technology, (eds) University of Aegean: Greece, pp. 1-8, 2013.

[22] Novak, J.T., Sadler, M.E. \& Murthy, S.N., Mechanisms of floc destruction during anaerobic and aerobic digestion and the effect on conditioning and dewatering of biosolids. Water Res., 37, pp. 3136-3144.

[23] Goel, R. \& Noguera, D., Evaluation of sludge yield and phosphorous removal in a cannibal solids reduction process. Journal of Envir. Eng., 132, pp. 1331-1337, 2006.

[24] Coma, M., Rovira, S., Canals, J. \& Colprim, J., Minimization of sludge production by a side-stream reactor under anoxic conditions in a pilot plant. Bioresource Technol., 129, pp. 229-235, 2013. 
[25] Datta, T., Liu, Y. \& Goel, R., Evaluation of simultaneous nutrient removal and sludge reduction using laboratori scale sequencing batch reactors. Chemosphere, 76, pp. 697-705, 2009.

[26] Chon, D.-H., Rome, M., Kim, H.-S. \& Park, C., Investigating the mechanism of sludge reduction in activated sludge with an anaerobic sidestream reactor. Water Science \& Technol., 63 (1), pp. 93-99, 2011.

[27] Kim, Y.M., Chon, D.-H., Kim, H.-S. \& Park, C., Investigation of bacterial community in activated sludge with an anaerobic side-stream reactor (ASSR) to decrease the generation of excess-sludge. Water Research, 26, pp. 4292-4300, 2012. 